\title{
VIABILIDADE TÉCNICO-ECONÔMICA DA UTILIZAÇÃO DE ENERGIA SOLAR NA UNIVASF - CAMPUS JUAZEIRO (BA)
}

\author{
Lucas Di Paula Gama dos Santos* \\ Francisco Ricardo Duarte** \\ Vivianni Marques Leite dos Santos***
}

RESUMO: O mundo vive uma nova fase tecnológica e para acompanhar este avanço, as fontes de energia convencionais já não são suficientes para manter o progresso. São necessárias fontes alternativas que complementem as matrizes energéticas. Essas fontes alternativas deverão focar na produção mais limpa e na sustentabilidade. Assim, neste cenário cada vez mais caótico de degradação ambiental, o termo sustentabilidade passou a ser um ponto chave para o desenvolvimento das empresas e está deixando de ser apenas um diferencial competitivo para ser incorporado à filosofia das empresas, constituindo uma questão de sobrevivência organizacional. No Nordeste, há alta incidência solar, a qual é geradora da maioria das outras fontes enérgicas. A Universidade Federal do Vale do São Francisco (UNIVASF), campus Juazeiro (BA), constituindo-se como uma instituição federal recente, onde funcionam diversos cursos de engenharia e local de desenvolvimento deste estudo, tem se mostrado como uma mola propulsora do desenvolvimento regional, sendo responsável pela geração de emprego e renda na região do Vale do São Francisco, bem como formando profissionais altamente qualificados em diferentes áreas. Sendo assim, neste artigo adotou-se uma metodologia que permitiu análise técnica e econômica da utilização da energia solar através de um sistema fotovoltaico nas instalações da UNIVASF, campus Juazeiro, que supra 100\% da demanda energética. Concluiu-se pela viabilidade técnica e econômica a médio prazo, com benefícios ambientais, sociais e econômicos para a instituição e para a região.

PALAVRAS-CHAVE: Fontes renováveis; Sistemas fotovoltaicos; Sustentabilidade.

\footnotetext{
* Pós-graduando em Gestão logística pela Faculdade São Francisco de Juazeiro - FASJ, Brasil.

** Doutor em Difusão do Conhecimento pela Universidade Federal da Bahia - UFBA. Docente Adjunto IV da Fundação Universidade Federal do Vale do São Francisco, Brasil.

*** Doutora em Química pela Universidade Federal de Pernambuco - UFPE. Docente-Associado III na UNIVASF. Coordenadora do Programa de Pós-Graduação em Propriedade Intelectual e Transferência de Tecnologia para Inovação no ponto focal UNIVASF. Docente Permanente no Programa de Pós-Graduação em nível de Doutorado em Agroecologia e Desenvolvimento Territorial, Brasil. E-mail: vivianni.santos@gmail.com
} 


\section{TECHNICAL AND ECONOMICAL VIABILIT Y IN THE USE OF SOLAR ENERGY IN UNIVASF, CAMPUS JUAZEIRO}

ABSTRACT: The world is living in a new technological phase and conventional energy sources are not sufficient to maintain the ongoing process. Alternative sources are required that supplement energy matrixes. They should focus on clean production and on sustainability. Within current chaotic environmental degradation, the term sustainability becomes a keyword for the development of companies. It is more than a competitive differential factor to be incorporated to the philosophy of firms. It is actually a question of organizational survival. Northeastern Brazil is characterized by high solar incidence that generates several energy sources. The Universidade Federal do Vale do São Francisco (UNIVASF), campus Juazeiro (BA), a recently-founded institution, with several engineering courses, has become a source for regional development. It has generated employment and earning in the region of the Vale do São Francisco, and has trained highly qualified professionals in different areas. Current paper deals with a technical and economic analysis of the use of solar energy with the photovoltaic system in UNIVASF, campus Juazeiro, supplying all energy demands. Results show the technical and economic viability at medium term, with environmental, social and economic benefits for the institution and the region.

KEY WORDS: Renewable sources; Photovoltaic systems; Sustainability.

\section{INTRODUÇÃO}

A crescente demanda global por produtos e serviços, a fim de saciar desejos e atender necessidades dos consumidores, provoca nas empresas, indústrias, instituições, de forma geral, o aumento demasiado da produção com avanços tecnológicos cada vez mais modernos, na busca por uma melhor posição competitiva (BRITO, 2016).

Para manter esse crescente progresso causado pela globalização, é preciso uma imensa quantidade de energia para sustentar essa produtividade, que atualmente encontra-se ainda, principalmente, dependente das fontes convencionais, tais como a fonte hidráulica e os combustíveis fósseis, principalmente o petróleo (CASTELLANELLI et al., 2008).

Nas últimas décadas, entretanto, diante do elevado potencial de poluição ambiental dos combustíveis fósseis (DRUMM et al., 2014), das diversas crises 
mundiais envolvendo o petróleo e do surgimento do conceito de sustentabilidade (CLARO; CLARO; AMÂNCIO, 2008), houve um aumento da demanda por energias mais limpas, de maneira a equilibrar a matriz energética mundial.

A energia elétrica é um fator preponderante para o bom funcionamento das universidades públicas federais, todavia, o aumento das contas de energia elétrica tem impactado negativamente no orçamento das mesmas, sendo, em parte, consequência da crise hídrica que assola boa parte do território nacional, logo, a utilização de outras fontes geradoras de energia, que apresentam um caráter poluidor, a exemplo das termoelétricas, culmina no aumento dos preços cobrados pelas concessionárias (NOGUEIRA, 2014).

Buscando evitar a dependência de fontes onerosas e poluidoras, bem como investir em matrizes energéticas renováveis, as pesquisas voltadas à energia solar têm evoluído e vem despertando o interesse da sociedade para sua utilização. Segundo Ferreira e Silva Filho (2009), a energia solar é ilimitada, podendo-se aproveitá-la tanto como fonte de calor quanto de luz, sendo hoje reconhecida como uma das alternativas energéticas mais promissoras. Pode-se dizer ainda que o sol é uma fonte primária, dando origem a inúmeras outras fontes existentes como a energia eólica e a maremotriz (CENTRO DE REFERÊNCIA PARA AS ENERGIAS SOLAR E EÓLICA SÉRGIO DE S. BRITO, 2008).

Estimativas da ANEEL - Agência Nacional de Energia Elétrica apontam que até 2024 o Brasil terá aproximadamente 1,2 milhão de residências autogeradoras de energia elétrica, utilizando-se de fontes renováveis, sendo que a energia solar terá participação em 15\% da matriz energética nacional (AGÊNCIA BRASIL, 2016). O documento ainda afirma que até 2030 , a energia solar fotovoltaica deverá movimentar $\mathrm{R} \$ 100$ bilhões no mercado brasileiro.

O Brasil é considerado um país privilegiado no que diz respeito à energia solar, destacando-se o fato do país possuir uma das maiores reservas de silício do mundo, contribuindo assim para produção de células solares. Em especial, na região Nordeste, onde está localizada a Fundação Universidade Federal do Vale do São Francisco (UNIVASF), ocorrem as maiores médias de radiação solar durante 0 ano (BRITO, 2016), evidenciando o interesse no tema abordado.

A UNIVASF, criada pela Lei $\mathrm{n}^{0} 10.473$, de 27 de junho de 2002, é uma 
instituição de ensino superior vinculada ao Ministério da Educação, com sede na cidade de Petrolina, Estado de Pernambuco, que tem como objetivo ministrar ensino superior, desenvolver pesquisas nas diversas áreas do conhecimento e promover a extensão universitária, caracterizando sua inserção regional mediante atuação multicampi no polo Petrolina (PE) e Juazeiro (BA), nos termos da Lei Complementar $\mathrm{n}^{\mathrm{o}} 113$, de 19 de setembro de 2001 , e do seu estatuto e normas de funcionamento, dando início às atividades acadêmicas em 2004 (UNIVERSIDADE FEDERAL DO VALE DO SÃO FRANCISCO, 2014).

Visando à redução do impacto dos custos com energia elétrica na UNIVASF, foi avaliada a viabilidade da utilização de energia solar no campus Juazeiro, que servirá como modelo para os demais campi, outro ponto importante a ser destacado é a promoção do uso de energias renováveis por meio da disseminação do conhecimento sobre o uso da energia solar no Vale do São Francisco, ligado a redução de custos, diminuição dos impactos ambientais negativos, desenvolvimento de mercado voltado à área energética e aproveitamento das fontes em abundância na região.

\section{MATERIAL E MÉTODOS}

A UNIVASF encontra-se localizada nos municípios baianos de Juazeiro, Senhor do Bonfim e Paulo Afonso; em Pernambuco, tem-se o campus Sede e o campus Ciências Agrárias (CCA), ambos em Petrolina; e, por fim, o campus São Raimundo Nonato, no Estado do Piauí.

A Fundação Universidade Federal do Vale do São Francisco (UNIVASF) é uma instituição de ensino superior vinculada ao Ministério da Educação, criada com o nome de Fundação Universidade Federal do Vale do São Francisco, legitimada pela Lei $\mathrm{n}^{\circ} .10 .473$, de 27 de junho de 2002, que a conferiu uma natureza fundacional, com sede na cidade de Petrolina, Estado de Pernambuco.

Sua missão é fomentar o desenvolvimento da região onde está localizada, a qual compreende parte de oito Estados do Nor- 
deste do país e o Norte de Minas Gerais, sendo que no ato de sua criação estava estabelecida fisicamente em três polos: 0 polo Petrolina, no Estado de Pernambuco, o polo de Juazeiro, no Estado da Bahia, e o polo de São Raimundo Nonato no Piauí, conforme previsto na Lei Complementar no 113 , de 19 de setembro de 2001 (BRASIL, 2013, p. 11).

Esta pesquisa, no que diz respeito aos critérios básicos, caracteriza-se como uma pesquisa aplicada, pois consoante Vergara (2006, p. 47) "a pesquisa aplicada é fundamentalmente motivada pela necessidade de resolver problemas concretos, mais imediatos, ou não".

No que se refere à abordagem da pesquisa, o presente estudo demonstra caráter exploratório, uma vez que, conforme Ganga (2012), trata-se de um assunto pouco explorado e amplo, permitindo uma vasta pesquisa, haja vista que o tema energia solar voltada a aplicações em universidades é um tema pouco explorado na literatura vigente.

\subsection{COLETA DE DADOS}

Para o desenvolvimento deste projeto foram levantados dados pertinentes à área/construção dos edifícios da UNIVASF, campus Juazeiro, através da Prefeitura Universitária (PU) e Secretaria de Infraestrutura. Também foram levantados dados relativos ao consumo e aos custos de energia elétrica a partir da Secretaria de Administração (SECAD) na UNIVASF.

A partir do levantamento dos dados, foram escolhidas as edificações que apresentam coberturas em laje, possibilitando o uso das mesmas para suportar as instalações fotovoltaicas e, portanto, não gerando custos extras para reforço das estruturas existentes. Foram levantados os custos dos equipamentos necessários para uma instalação fotovoltaica conectada à rede elétrica (On-Grid) com empresas atuantes no setor de energia solar da região circunscrita. Para todos os aspectos a serem avaliados neste trabalho, foi considerada a latitude de $9,413889^{\circ}$ Sul e longitude de $40,502778^{\circ}$ Oeste.

Para desenvolver um estudo sobre a utilização de energia solar, sendo 
sua finalidade voltada à energia elétrica ou para o uso do aquecimento de água, é fundamental que se conheça as características de radiação solar da região. Para a coleta destes dados foi utilizado o programa Sundata, o qual está voltado ao cálculo da radiação solar diária média mensal em qualquer ponto do território nacional e está disponível no portal do Centro de Referência de Energia Solar e Eólica Sergio Brito (CENTRO DE REFERÊNCIA PARA AS ENERGIAS SOLAR E EÓLICA SÉRGIO DE S. BRITO, 2008).

\subsection{CÁLCULO DO DIMENSIONAMENTO DAS PLACAS E DO INVERSOR}

Com base na média de consumo, foi necessário verificar a potência, o tamanho e o custo das placas/inversores disponíveis no mercado. Em seguida, é realizado o Cálculo do Dimensionamento (CD) das placas e dos inversores por meio da Equação 1 (SANPOWER, 2017), descrita a seguir.

$$
C D=\frac{\left(\frac{\left(\frac{\text { Média do consumo de energia em 2016 }}{30}\right)}{\text { radiação solar média diária }}\right) x 1000}{\text { Potência das placas/inversores }}
$$

(Equação 1)

Onde as respectivas unidades de medidas são:

$\mathrm{CD} \rightarrow$ Quantidade de placas/inversores;

Média do consumo da energia consumida em $2016 \rightarrow \mathrm{kWh}$;

Radiação solar média diária $\rightarrow \mathrm{kWh} \cdot \mathrm{m}^{-2}$ dia;

Potência das placas $\rightarrow \mathrm{W}$ e inversores $\rightarrow \mathrm{kWp}$.

O cálculo permite obter quantas placas são necessárias para abastecer todo o sistema, bem como o número de inversores que estariam acoplados ao conjunto de painéis fotovoltaicos, complementando o sistema. 


\subsection{ANÁLISE DE INVESTIMENTO}

A estimativa de um investimento constitui parâmetros de viabilidade, com o objetivo de ajustar o retorno aos proprietários desse capital, permitindo avaliar alternativas (LIZOTE et al., 2014). Assim, para obter sucesso na sua opção é necessário mensurar os resultados dos reflexos financeiros. A aplicação de vários métodos para embasar e dar credibilidade é fundamental para analisar as alternativas de investimento (URTADO et al., 2009). Foram utilizados dois métodos conhecidos para avaliação deste investimento, o Valor Presente Líquido (VPL) e o Payback ou prazo de recuperação do investimento.

O Payback é o tempo que o investimento ou empréstimo leva para ser quitado, ou seja, a quantidade de período que se leva para recuperar o investimento ou o tempo que o investimento leva para zerar seu fluxo acumulado. O cálculo do Payback é desenvolvido de acordo com a seguinte Equação 2 (MOTTA et al., 2009):

$$
\text { Payback }=\frac{V i}{V E R}
$$

Onde:

$\mathrm{Vi} \rightarrow$ Valor do investimento $(\mathrm{R} \$)$;

$\mathrm{VER} \rightarrow$ Valor esperado da Receita $(\mathrm{R} \$)$.

O VPL é o resultado que o investimento proporcionará no final do projeto, utilizando a Taxa Mínima de Atratividade (TMA), ou seja, a soma dos valores presentes de cada um dos fluxos de caixa - tanto positivos como negativos - que ocorrem ao longo da vida do projeto (URTADO et al., 2009).

O cálculo do VPL é desenvolvido de acordo com a Equação 3 (MOTTA et al., 2009):

$$
V P L=\sum_{j=1}^{n} \frac{F C j}{(1+i)^{j}}-F C_{0}
$$

Onde:

(Equação 3)

$\mathrm{FCj} \rightarrow$ Valores de entrada ou saída do caixa em cada período de tempo $(\mathrm{R} \$)$; 
$\mathrm{FC}_{0} \rightarrow$ Valor do investimento inicial ( $\mathrm{R} \$$ );

$\mathrm{j} \rightarrow$ Período de tempo (ano);

$\mathrm{i} \rightarrow$ Taxa de desconto do projeto (a.a.).

\section{RESULTADOS E DISCUSSÃO}

Tendo em vista que todas essas unidades administrativas do poder executivo federal vêm passando por dificuldades financeiras devido à atual crise políticoeconômica, nos quais os cortes de verba dos serviços básicos vêm sendo constante causa de preocupação.

A energia elétrica necessária para manter os campi ativos tem elevado peso nos custos, pois, problemas como a crise hídrica que vem assolando boa parte do território nacional culminaram na utilização de outras fontes energéticas onerosas como as termoelétricas e consequentemente impactaram na elevação do custo da energia elétrica.

A análise dos dados obtidos com os departamentos que constituem a administração da UNIVASF permitiu concluir que os campi de Juazeiro e PetrolinaSede despontam com os custos mais elevados no tocante ao consumo de energia elétrica.

No caso da UNIVASF Petrolina-Sede o elevado custo está associado ao funcionamento da maior parte dos departamentos administrativos, incluindo a reitoria e pró-reitorias, o Hospital Universitário (HU) e instalações para 6 cursos de graduação. Para o campus UNIVASF Juazeiro, o elevado consumo está ligado ao espaço físico que é composto por 35 laboratórios (processos químicos, mecânicos, computacionais, entre outros), biblioteca, restaurante universitário (RU), galpão de artes, bloco dos colegiados, bloco de salas de aula, com 29 salas para dar suporte aos 8 cursos de graduação existentes. Além disso, há também o complexo multieventos, que dá apoio aos eventos científicos, culturais e artísticos da universidade e comunidade externa. Ainda há a instalação conhecida como Espaço Plural, onde encontra-se sob a direção da pró-reitoria de extensão (PROEX), apesar de não se encontrar nas instalações da UNIVASF Juazeiro, está sob sua responsabilidade financeira e administrativa. 
Neste contexto, com base nos dados coletados sobre os custos envolvendo energia elétrica das 6 unidades, durante o ano de 2016, algumas contas (março, maio e outubro) os valores superaram cento e quarenta mil reais ( $\mathrm{R} \$ 140.000,00)$ (campus sede Petrolina), sendo que muitas outras ultrapassam cem mil reais (R\$ $100.000,00)$ durante o ano. Fato este que constata a necessidade de investimentos no setor, para mitigar o impacto nos custos finais da instituição.

No Gráfico 1, verifica-se o valor acumulado no ano de 2016, por campus, dos custos com energia elétrica, revelando montantes elevados, que permitem concluir o quão oneroso é para a universidade o consumo de energia elétrica, deixando-a muitas vezes em situações delicadas, haja vista que ainda há inúmeras outras despesas e custos, além da conta de energia elétrica.

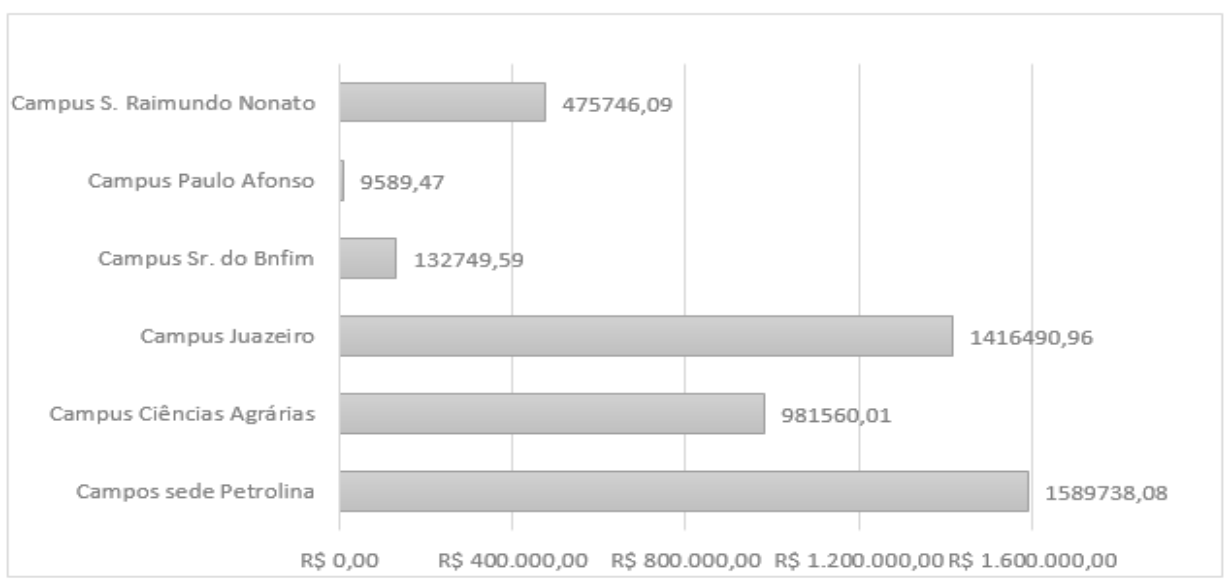

Gráfico 1. Valor montante anual dos custos de energia elétrica por campus da UNIVASF 2016

$O$ custo anual de $\mathrm{R} \$ 4.605 .874,20$ para a universidade com suprimento energético torna a questão em si alarmante, sendo que deste montante, 65,3\% correspondem às unidades de Juazeiro e Petrolina-Sede, mostrando que se faz necessário tomar decisões importantes o quanto antes, e que o investimento em energias renováveis se apresenta como uma saída viável para a atual crise, além de ser esperada uma postura exemplar para as instituições de reduzir seus custos com energia elétrica com sustentabilidade na prática. 
O campus Juazeiro, objeto do presente estudo, está instalado onde funcionava a indústria de beneficiamento de polpa de tomate da Cica Norte. A unidade de Juazeiro com seus $145.595 \mathrm{~m}^{2}$, ao longo do ano de 2016, acarretou em despesa de $\mathrm{R} \$ 1.416 .490,96$ para instituição no que diz respeito à energia elétrica (Gráfico 1). Este valor corresponde a aproximadamente 31\% do total, sendo infimamente inferior aos custos da unidade de Petrolina-Sede com 34,3\% e superior aos demais campi.

Neste campus verificam-se ainda espaços disponíveis e coberturas em laje que podem servir para aproveitamento de instalação de uma usina solar (On-Grid), haja vista que a demanda de energia é alta, sendo então necessária uma geração acima de $5 \mathrm{MW}$, superando as categorias micro usina $(\leq 75 \mathrm{~kW})$ e mini usina $(>75$ kW e $\leq 5$ MW) (ANEEL, 2012).

De acordo com a resolução 482 de 2012, homologada pela Aneel, é permitida aos consumidores cativos a possibilidade de gerar sua própria energia conectada à rede (ANEEL, 2012). Essa decisão permite que a energia gerada pelo consumidor seja abatida da sua conta e caso a energia gerada seja maior do que a consumida no mês, o excesso é convertido em crédito com validade de 5 anos (60 meses).

Esse crédito pode ser utilizado, futuramente, na unidade em que foi gerado, ou na conta de outras unidades que o consumidor venha a possuir vinculado ao mesmo Cadastro Nacional de Pessoa Jurídica (CNPJ) ou Cadastro de Pessoa Física (CPF). Vale ressaltar que não há abatimento da Contribuição de Iluminação Pública (CIP) e da taxa mínima cobrada pela concessionária. Recentemente, houve uma revisão na resolução permitindo o compartilhamento dos créditos gerados por empreendimentos de múltiplas unidades consumidoras, tais como condomínios, consórcios ou cooperativas.

Em 2015 o CONFAZ - Conselho Nacional da Política Fazendária, que está ligado ao Ministério da Fazenda, através do Ajuste SINIEF 2, revogou o Convênio que orientava a tributação da energia injetada na rede. Cada Estado passou a decidir se tributa ou não a energia solar que é injetada na rede da distribuidora (BRASIL, 2015). No entanto, ainda há Estados que não isentaram a energia solar de ICMS. São eles Amazonas, Paraná e Santa Catarina, sendo então o ICMS um tributo isentado nas outras unidades da federação. 
A Figura 1, a seguir, contribui para explicar o funcionamento do sistema fotovoltaico On-Grid. De acordo com esse sistema, o painel fotovoltaico capta a luz e produz energia elétrica (energia fotovoltaica). Os painéis, instalados sobre o seu telhado, são conectados uns aos outros e então conectados ao inversor de corrente. $\mathrm{O}$ inversor converte a energia solar dos painéis fotovoltaicos - corrente contínua (CC) em energia elétrica - corrente alternada (CA). A energia que sai do inversor solar segue para o "quadro de luz", sendo então distribuída para as instalações da UNIVASF Juazeiro, e assim reduzindo a quantidade de energia consumida proveniente da distribuidora.

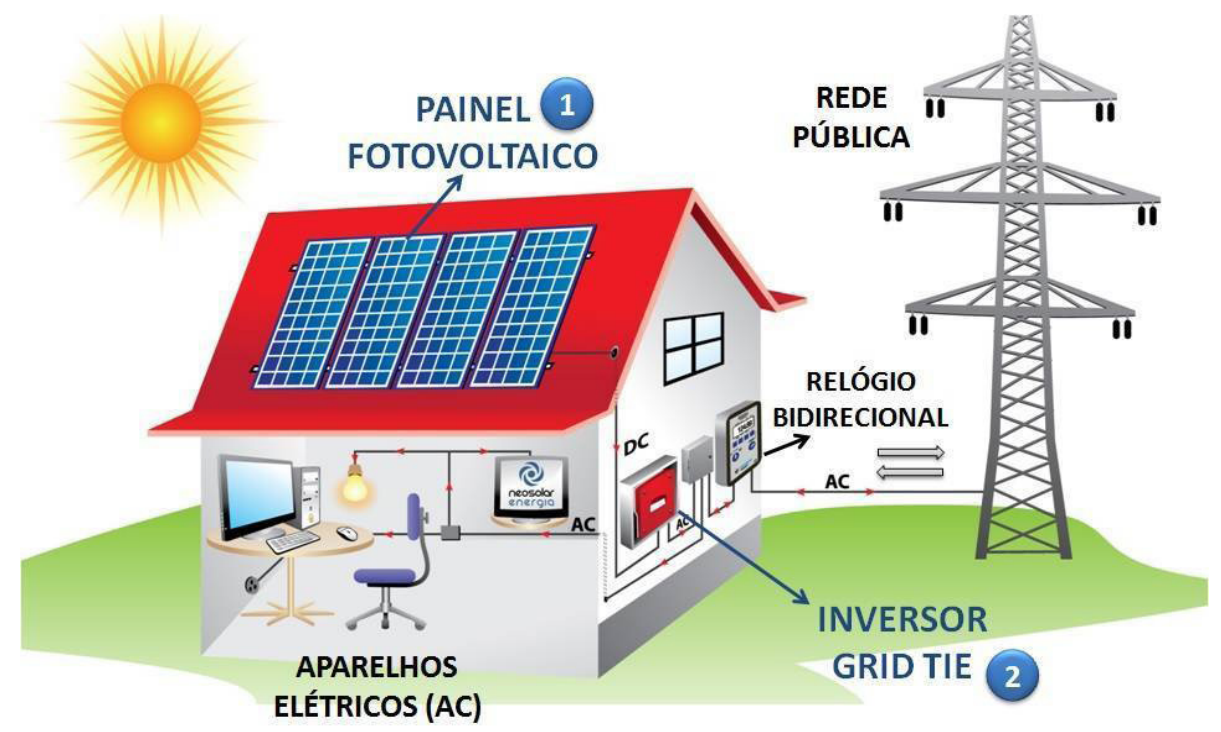

Figura 1. Funcionamento do sistema fotovoltaico On-Grid Fonte: Santos, Santos e Duarte (2017)

Finalmente, de acordo com o sistema On-Grid, a produção de eletricidade segue para a rede elétrica através do relógio medidor de energia (relógio de luz bidirecional). Esse relógio mede a energia distribuída que é consumida e a energia injetada na rede da distribuidora, que em caso de geração adicional de energia fotovoltaica, torna-se possível o acúmulo de "créditos de energia" para a utilização em até 5 anos. 


\subsection{INSTALAÇÃO DA USINA SOLAR}

A Tabela 1 contém valores do consumo de energia nos 12 meses de 2016, que expõe uma expressiva variação e revela um pico no mês de junho de 2016.

Com base no consumo de energia elétrica da UNIVASF e a radiação solar média diária, aqui descritos na Tabela 1, calculou-se a média de consumo de 2016 que foi de $138.952 \mathrm{kWh}$.mês ${ }^{-1}$. A radiação solar média diária para a cidade de Juazeiro (BA) foi adquirida pelo programa Sundata, sendo de 5,37 kWh.m.-2 dia (CENTRO DE REFERÊNCIA PARA AS ENERGIAS SOLAR E EÓLICA SÉRGIO DE S. BRITO, 2008).

Tabela 1. Consumo da UNIVASF e radiação solar em 2016

\begin{tabular}{ccc}
\hline Mês & Consumo de energia elétrica $-\mathbf{k W h}$ & radiação solar média diária $\cdot \mathbf{k W h} \cdot \mathbf{m}^{-2} \mathbf{d i a}$ \\
\hline Jan/16 & 102.984 & 5,61 \\
$\mathrm{Fev} / 16$ & 134.904 & 6,5 \\
$\mathrm{Mar} / 16$ & 84.420 & 5,47 \\
$\mathrm{Abr} / 16$ & 175.518 & 5 \\
Mai/16 & 174.300 & 4,86 \\
$\mathrm{Jun} / 16$ & 188.664 & 4,5 \\
$\mathrm{Jul} / 16$ & 147.651 & 4,67 \\
Ago/16 & 164.010 & 5,19 \\
Set/16 & 148.008 & 5,42 \\
Out/16 & 178.542 & 5,97 \\
Nov/16 & 88.788 & 5,72 \\
Dez $/ 16$ & 79.632 & 5,56 \\
\hline Média & $\mathbf{1 3 8 . 9 5 2}$ & $\mathbf{5 , 3 7}$ \\
\hline
\end{tabular}

Finalmente, para casas e empresas, tradicionalmente, se utiliza a placa solar de 60 células. Elas possuem aproximadamente 1,00 m x 1,65 m e pesam em torno de $18-20 \mathrm{~kg}$ cada. As potências dessas placas fotovoltaicas variam de 240, 245, 250, 255, 260, 265 até 270 Watts (SANPOWER, 2017). As mais eficientes estão acima de 250 Watts. A placa com maior potência utilizada no país é de $320 \mathrm{~W}$, configurando-se assim a com maior nível de eficiência (16,42\%), como também a maior em tamanho físico (1,00 m x 1,96 m) (SANPOWER, 2017). 
Logo, o cálculo do CD, utilizando-se da Equação 1, indicou a necessidade de 2.695 placas com potência de $320 \mathrm{~W}$. Efetuando-se o mesmo cálculo para os inversores, resultou em uma quantidade de 43 inversores de $20 \mathrm{kWp}$.

Sendo assim, o investimento para aquisição desta usina solar com potência de $862,40 \mathrm{kWp}$ para abastecer $100 \%$ da demanda energética da UNIVASF Juazeiro foi obtida a partir dos seguintes quesitos: descrição, quantidade, valor unitário e valor total (Tabela 2). A mesma tabela ainda contém análise comparativa entre modelos de placas e modelos de inversores justificando a escolha dos modelos do estudo.

Tabela 2. Descrição do projeto

\begin{tabular}{|c|c|c|c|c|}
\hline \multicolumn{2}{|c|}{ Descrição } & Quantidade & Valor Unitário (R\$) & $\begin{array}{l}\text { Valor total } \\
\quad(\mathbf{R} \$)\end{array}$ \\
\hline \multicolumn{2}{|c|}{ Painel - $320 \mathrm{~W}$} & 2695 & 844,00 & $2.274 .580,00$ \\
\hline \multicolumn{2}{|c|}{ Inversor BB Power - $20 \mathrm{kWp}$} & 43 & $21.255,72$ & $913.995,96$ \\
\hline \multicolumn{2}{|c|}{ Estruturas e acessórios mecânicos - Kit } & 1 & $595.149,66$ & $595.149,66$ \\
\hline \multicolumn{2}{|c|}{ Proteção e material elétrico - Kit } & 1 & $362.520,14$ & $362.520,14$ \\
\hline \multicolumn{4}{|c|}{ Valor por Watt - 2,64 $\mathrm{R} \$ / \mathrm{W}$} & $4.146 .245,76$ \\
\hline \multicolumn{5}{|c|}{ Valores comparativos entre placas e entre inversores } \\
\hline Placas (W) & Custo $(\mathbf{R} \$)$ & Área $\left(m^{2}\right)$ & $\begin{array}{l}\text { Quantidade } \\
\text { (uni) }\end{array}$ & Custo Final (R\$) \\
\hline 320 & 844,00 & 5822 & 2695 & $2.274 .580,00$ \\
\hline 250 & 800,00 & 6383 & 3450 & $2.760 .000,00$ \\
\hline Inversores (kWp) & Custo (R\$) & \multicolumn{2}{|c|}{ Quantidade (uni) } & Custo Final (R\$) \\
\hline 20 & $21.255,72$ & \multicolumn{2}{|c|}{43} & $913.995,96$ \\
\hline 8,2 & $14.190,00$ & \multicolumn{2}{|c|}{105} & $39.950,00$ \\
\hline
\end{tabular}

Fonte: Sanpower (2017).

O fato de usar o inversor mais caro do mercado brasileiro, bem como as placas de maior potência do mercado, resulta em uma quantidade de equipamentos menor, gerando um custo final menor. Comparando-se isto com placas e inversores 
de menor potência têm-se uma redução no custo unitário, todavia o maior número de equipamentos para suprir a demanda culmina em um valor final mais elevado, bem como menor eficiência e maior área de utilização na maioria dos casos (Tabela 2).

A utilização de um inversor de $8,2 \mathrm{kWp}$, no valor de $\mathrm{R} \$ 14.190,00$, resultaria usando o mesmo cálculo de dimensionamento em 105 inversores, que refletiria no montante final de $\mathrm{R} \$ 1.489 .950,00$, ou seja, $\mathrm{R} \$ \mathbf{5 7 5 . 9 5 4 , 0 4}$ a mais no orçamento. Comparando-se com painéis solares, utilizando placas de $250 \mathrm{~W}$, seriam necessárias 3450 placas, que cobririam $6383 \mathrm{~m}^{2}$, enquanto para as placas de $320 \mathrm{~W}$, a área utilizada seria de $5822 \mathrm{~m}^{2}$, sendo $561 \mathrm{~m}^{2}$ a mais para instalação. Quanto ao custo, uma placa de $250 \mathrm{~W}$ custaria em média $\mathrm{R} \$ 800,00$ e resultaria no montante final de dois milhões e setecentos e sessenta mil reais ( $\mathrm{R} \$ 2.760 .000,00)$, logo, teria uma elevação no orçamento final de $\mathrm{R} \$ 485.420,00$, encarecendo o investimento.

Outra alternativa seria estudar a viabilidade técnica de se compartilhar placas com o Complexo Multieventos (auditório para 600 lugares, que abriga também 8 mini-auditórios com capacidade de 120 lugares cada um, fora banheiros e área administrativa), sendo esta a edificação com maior área de laje $\left(4117,89 \mathrm{~m}^{2}\right)$. Devido ao seu tamanho, esta instalação também apresenta grande demanda energética, sendo que o mesmo também apresenta estrutura em laje, que, de acordo com o projeto, suporta a instalação On-Grid, facilitando a instalação e evitando custos com estrutura predial.

Vale lembrar que para que seja efetuada a instalação de uma usina solar, se faz necessário o cumprimento das normas regulamentadoras (NR) específicas para tal. Dentre elas as principais são: NR 10 (BRASIL, 2004), NR 11 (BRASIL, 1978a), NR 15 (BRASIL, 1978b), NR 35 (BRASIL, 2012), que tratam da segurança dos operadores na prestação de serviço, e as normas específicas para sistema fotovoltaico, tais como: NBR IEC 62116:2012 (ABNT, 2012); NBR 16145:2013 (ABNT, 2013a) e 16149:2013 (ABNT, 2013b); NBR 16274:2014 (ABNT, 2014) e Portaria 004/2011 (INMETRO, 2011).

A produção energética ao longo do ano estaria ligada à capacidade de geração da usina $(862,40 \mathrm{kWp})$ e a radiação solar média diária que varia ao longo do ano, sendo que nos meses de alta produção gerariam créditos de energia junto 
à concessionária que retornariam para a UNIVASF nos meses de baixa produção (Gráfico 2).

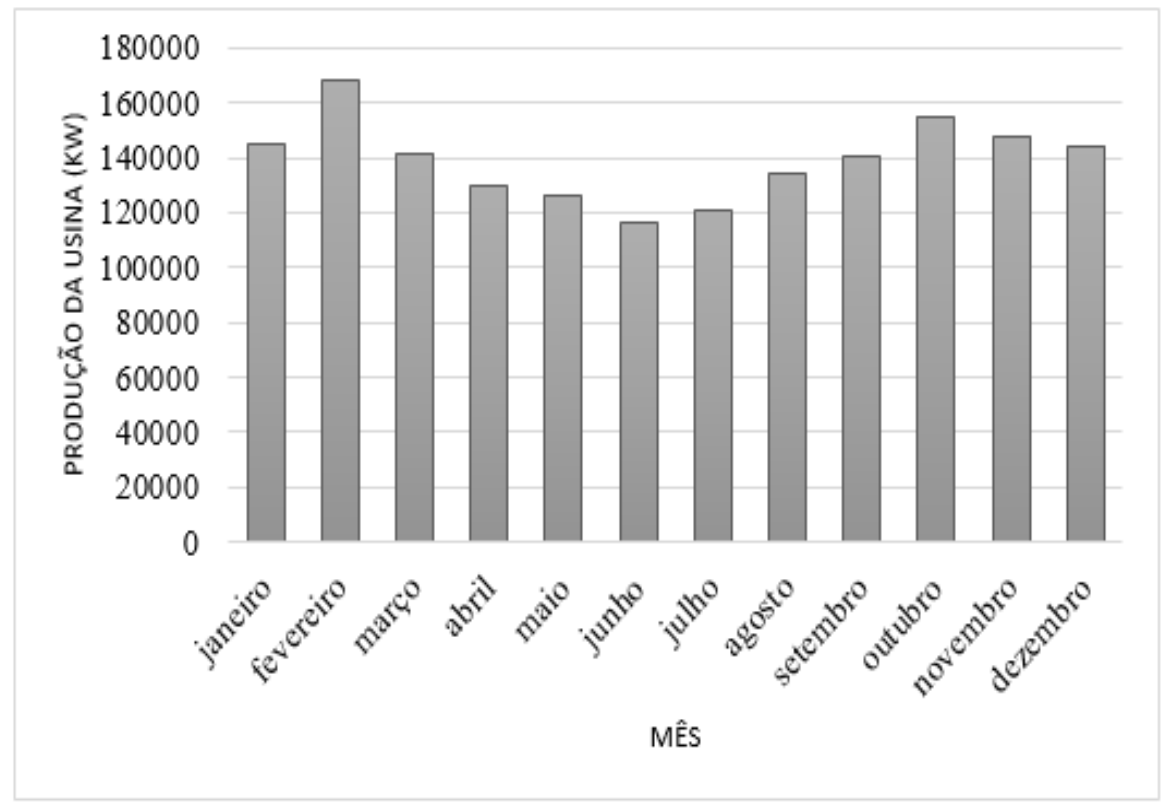

Gráfico 2. Geração da usina solar

Como pode-se verificar na Gráfico 2, os meses de maior consumo de energia se concentram de janeiro a junho, com pico em fevereiro e novamente de agosto a dezembro, com novo pico em outubro. Isto reflete os períodos de aula nos cursos de graduação. $\mathrm{O}$ consumo ocorre ao longo de todo o ano devido às atividades da pósgraduação e de pesquisa e extensão, cuja maioria se mantém durante os períodos de recesso.

\subsection{ANÁLISE DE INVESTIMENTO}

O cálculo de VPL utilizado para este investimento em energia solar levou em consideração a taxa anual da poupança em 2016, que foi de $8,3 \%$ a. a. (trata-se do rendimento nominal, isto é, sem descontar a inflação) como TMA, sendo a poupança a principal comparação ao se fazer um investimento. 
Foi ainda empregada mais uma taxa, o reajuste tarifário da Coelba foi homologado pela Resolução $\mathrm{n}^{\circ} 2.066$, de 19/04/2016, ANEEL, no percentual de $10,64 \%$ para os consumidores de grande porte, sendo estes atendidos em alta tensão (COELBA, 2016). A taxa de 10,64\% foi usada para fazer as projeções pelos próximos 25 anos, que é o tempo de vida do projeto (Tabela 3).

Tabela 3. Cálculo de VPL para projeto de usina solar

(Continua)

\begin{tabular}{|c|c|c|}
\hline \multicolumn{2}{|c|}{ Taxa de Retorno - (\%) } & 8,30 \\
\hline \multicolumn{2}{|c|}{ Alteração Tarifária - (\%) } & 10,64 \\
\hline \multicolumn{2}{|c|}{ VPL - (R\$) } & $36.235 .887,33$ \\
\hline Período & Ano & Fluxo de Caixa (CF) - R\$ \\
\hline 0 & 2017 & $-4.146 .245,76$ \\
\hline 1 & 2018 & $1.337 .598,06$ \\
\hline 2 & 2019 & $1.479 .918,49$ \\
\hline 3 & 2020 & $1.637 .381,82$ \\
\hline 4 & 2021 & $1.811 .599,25$ \\
\hline 5 & 2022 & $2.004 .353,41$ \\
\hline 6 & 2023 & $2.217 .616,61$ \\
\hline 7 & 2024 & $2.453 .571,02$ \\
\hline 8 & 2025 & $2.714 .630,97$ \\
\hline 9 & 2026 & $3.003 .467,71$ \\
\hline 10 & 2027 & $3.323 .036,67$ \\
\hline 11 & 2028 & $3.676 .607,77$ \\
\hline 12 & 2029 & $4.067 .798,84$ \\
\hline 13 & 2030 & $4.500 .612,64$ \\
\hline 14 & 2031 & $4.979 .477,82$ \\
\hline 15 & 2032 & $5.509 .294,26$ \\
\hline 16 & 2033 & $6.095 .483,17$ \\
\hline 17 & 2034 & $6.744 .042,58$ \\
\hline 18 & 2035 & $7.461 .608,71$ \\
\hline 19 & 2036 & $8.255 .523,88$ \\
\hline 20 & 2037 & $9.133 .911,62$ \\
\hline 21 & 2038 & $10.105 .759,82$ \\
\hline 22 & 2039 & $11.181 .012,66$ \\
\hline
\end{tabular}


(Conclusão)

\begin{tabular}{ccc}
\hline \multicolumn{2}{c}{ Taxa de Retorno - (\%) } & 8,30 \\
\hline \multicolumn{2}{c}{ Alteração Tarifária - (\%) } & 10,64 \\
\hline \multicolumn{2}{c}{ VPL - (R\$) } & $36.235 .887,33$ \\
\hline Período & Ano & Fluxo de Caixa (CF) - R\$ \\
\hline 23 & 2040 & $12.370 .672,41$ \\
24 & 2041 & $13.686 .911,95$ \\
25 & 2042 & $15.143 .199,39$ \\
\hline
\end{tabular}

A composição do VPL (Tabela 3) ao longo dos 25 anos, que é o tempo de vida útil das placas, teria um retorno ao final deste período de $\mathrm{R} \$ 36.235 .887,33$, configurando-se assim uma significativa economia para a UNIVASF em termos energéticos.

O investimento na usina solar, segundo o cálculo do Payback (Tabela 4), apresentaria retorno com 3 anos e 3 meses após a instalação, consequentemente, o tempo restante de vida útil do projeto seria de economia para a instituição, mostrando-se viável do ponto de vista econômico.

Tabela 4. Cálculo de Payback para o projeto de usina solar

\begin{tabular}{ccccc}
\hline \multicolumn{2}{c}{ Taxa de Retorno - (\%) } & \multicolumn{2}{c}{8,30} & \multicolumn{2}{c}{ Payback } \\
\hline \multicolumn{2}{c}{ Alteração Tarifária - (\%) } & 10,64 & 3 anos & 3 meses \\
\hline Período & Ano & Fluxo de Caixa (CF) - R\$ & (VPL) - R\$ & Saldo (R\$) \\
\hline 0 & 2017 & $-4.146 .245,76$ & $-4.146 .245,76$ & - \\
1 & 2018 & $1.337 .598,06$ & $1.235 .085,93$ & $-2.911 .159,83$ \\
2 & 2019 & $1.479 .918,49$ & $1.261 .772,00$ & $-1.649 .387,84$ \\
3 & 2020 & $1.637 .381,82$ & $1.289 .034,66$ & $-360.353,18$ \\
4 & 2021 & $1.811 .599,25$ & $1.316 .886,38$ & $956.533,20$ \\
5 & 2022 & $2.004 .353,41$ & $1.345 .339,88$ & $2.301 .873,08$ \\
6 & 2023 & $2.217 .616,61$ & $1.374 .408,16$ & $3.676 .281,24$ \\
7 & 2024 & $2.453 .571,02$ & $1.404 .104,52$ & $5.080 .385,76$ \\
8 & 2025 & $2.714 .630,97$ & $1.434 .442,51$ & $6.514 .828,27$ \\
9 & 2026 & $3.003 .467,71$ & $1.465 .436,00$ & $7.980 .264,27$ \\
10 & 2027 & $3.323 .036,67$ & $1.497 .099,16$ & $9.477 .363,43$ \\
11 & 2028 & $3.676 .607,77$ & $1.529 .446,46$ & $11.006 .809,89$ \\
& & & & \\
\hline
\end{tabular}


(Conclusão)

\begin{tabular}{ccccc}
\hline \multicolumn{2}{c}{ Taxa de Retorno - (\%) } & 8,30 & \multicolumn{2}{c}{ Payback } \\
\hline \multicolumn{2}{c}{ Alteração Tarifária - (\%) } & 10,64 & 3 anos & 3 meses \\
\hline Período & Ano & Fluxo de Caixa (CF) - R\$ & (VPL) - R & Saldo (R\$) \\
12 & 2029 & $4.067 .798,84$ & $1.562 .492,67$ & $12.569 .302,56$ \\
13 & 2030 & $4.500 .612,64$ & $1.596 .252,90$ & $14.165 .555,46$ \\
14 & 2031 & $4.979 .477,82$ & $1.630 .742,57$ & $15.796 .298,04$ \\
15 & 2032 & $5.509 .294,26$ & $1.665 .977,46$ & $17.462 .275,49$ \\
16 & 2033 & $6.095 .483,17$ & $1.701 .973,64$ & $19.164 .249,14$ \\
17 & 2034 & $6.744 .042,58$ & $1.738 .747,59$ & $20.902 .996,73$ \\
18 & 2035 & $7.461 .608,71$ & $1.776 .316,10$ & $22.679 .312,83$ \\
19 & 2036 & $8.255 .523,88$ & $1.814 .696,34$ & $24.494 .009,16$ \\
20 & 2037 & $9.133 .911,62$ & $1.853 .905,84$ & $26.347 .915,00$ \\
21 & 2038 & $10.105 .759,82$ & $1.893 .962,53$ & $28.241 .877,54$ \\
22 & 2039 & $11.181 .012,66$ & $1.934 .884,71$ & $30.176 .762,25$ \\
23 & 2040 & $12.370 .672,41$ & $1.976 .691,09$ & $32.153 .453,34$ \\
24 & 2041 & $13.686 .911,95$ & $2.019 .400,76$ & $34.172 .854,09$ \\
25 & 2042 & $15.143 .199,39$ & $2.063 .033,24$ & $36.235 .887,33$ \\
\hline
\end{tabular}

Com base no tempo de vida útil de 25 anos e tempo de Payback de 3 anos e 3 meses estima-se uma economia de, aproximadamente, 31 milhões de reais após 25 anos da instalação, o que poderia ser revertido para outros fins de custeio, conforme planejamento institucional e liberação de recursos.

O uso da energia solar impacta positivamente por diminuir a demanda pela fonte hídrica proveniente da barragem de Sobradinho, além da redução de gases nocivos e impactantes sobre o efeito estufa.

Vale lembrar que alguns investimentos poderão ser necessários ao longo destes 25 anos, pois a vida útil dos inversores, bem como das estruturas metálicas, é menor do que a vida útil das placas (25 anos). Os inversores têm vida útil de 6 anos, ou seja, a cada 6 anos será necessário substituí-los, sendo então previstas 4 substituições ao longo dos 25 anos, custando, em valores atuais, para a UNIVASF R\$ 3.655.983,84.

As estruturas metálicas têm uma duração de 15 anos, culminando na 
previsão de uma única modificação ao longo de 25 anos, que custaria à UNIVASF $\mathrm{R} \$ 595.149,66$. Ao final ocorreria um abatimento no montante de $\mathrm{R} \$ 36.235 .887,33$, sendo então a redução de custos totais com energia elétrica de $\mathrm{R} \$ 31.984 .753,83$, um total ainda bastante representativo, sendo este um estímulo para o investimento da instalação de usinas em outros campi.

\section{CONSIDERAÇÕES FINAIS}

O avanço das fontes renováveis vem progredindo rapidamente nos últimos anos e, tendo em vista o grande potencial de radiação solar em nossa região, as perspectivas de crescimento para a geração de energia fotovoltaica são as melhores possíveis, abrindo um novo mercado para o segmento de projeção e implantação de sistemas fotovoltaicos residenciais, comerciais, industriais, rurais e etc.

O investimento para aquisição deste projeto custaria aos órgãos responsáveis $\mathrm{R} \$ 4.146 .245,76$, sendo que a usina teria capacidade de geração de $862,40 \mathrm{kWp}$, que seria quitado em 3 anos e 3 meses consoante o cálculo de payback, após entrar em funcionamento. $\mathrm{O}$ fato das placas apresentarem uma vida útil de 25 anos garantiu através do VPL uma economia para a instituição de $\mathrm{R} \$ 36.235 .887,33$, após quitado o investimento, pelos próximos 21 anos e 9 meses, destacando que os custos com mão de obra já se encontram inclusos nos valores levantados.

Por fim, espera-se que esta pesquisa possa servir como informação básica para a tomada de decisão, caso a UNIVASF venha a planejar investimentos em soluções energéticas sustentáveis, objetivando então mitigar as despesas da universidade com energia elétrica. Agindo assim, poderá vir a ser um exemplo para os outros campi, bem como para a comunidade em geral.

\section{REFERÊNCIAS}

ABNT. NBR 16145: Sistemas fotovoltaicos (FV) - características de interface de conexão com a rede elétrica de distribuição - procedimento de ensaio de conformidade. Rio de Janeiro: ABNT, 2013a. 
ABNT. NBR 16149: Sistemas fotovoltaicos (FV) - características de interface de conexão com a rede elétrica de distribuição. Rio de Janeiro: ABNT, 2013b.

ABNT. NBR 16274: Sistemas fotovoltaicos conectados à rede - requisitos mínimos para documentação, ensaios de comissionamento, inspeção e avaliação de desempenho. Rio de Janeiro: ABNT, 2014.

ABNT. NBR IEC 62116: Procedimento de ensaio de anti-ilhamento para inversores de sistemas fotovoltaicos conectados à rede elétrica. Rio de Janeiro: ABNT, 2012b.

AGÊNCIA BRASIL. Em oito anos, 1,2 milhão de residências vão gerar sua própria energia. 2016. Disponível em: http://www.brasil.gov.br/noticias/infraestrutura/2016/03/em-oito-anos-1-2-milhao-de-residencias-vao-gerar-sua-propria-energia-1. Acesso em: 5 abr. 2017.

ANEEL. Resolução normativa $\mathbf{n}^{\circ}$ 482, de 17 de abril de 2012. Estabelece as condições gerais para o acesso de microgeração e minigeração distribuída aos sistemas de distribuição de energia elétrica, o sistema de compensação de energia elétrica, e dá outras providências. 2012. Disponível em: http://www2.aneel.gov.br/cedoc/ bren2012482.pdf. Acesso em: 20 mar. 2017.

BRASIL. Ministério da Economia. Conselho Nacional de Política Fazendária. Ajuste SINIEF 2, de 22 de abril de 2015. Dispõe sobre os procedimentos relativos às operações de circulação de energia elétrica, sujeitas a faturamento sob o Sistema de Compensação de Energia Elétrica de que trata a Resolução Normativa $n^{0} 482$, de 2012, da Agência Nacional de Energia Elétrica - ANEEL. 2015. Disponível em: https://www.confaz.fazenda.gov.br/legislacao/ajustes/2015/AJ_002_15\#wrapper. Acesso em: 25 abr. 2018.

BRASIL. Ministério da Educação. Coordenação de Aperfeiçoamento de Pessoal de Nível Superior. Diretoria de Educação a Distância. Programa Nacional de Formação em Administração Pública. Projeto pedagógico do curso bacharelado em administração pública modalidade a distância. Petrolina: MEC, 2013. Disponível em: http://www.sead.univasf.edu.br/administrator/arquivos/BACHARELADO\%20EM\%20 ADM\%20PUBLICA_PCC.pdf. Acesso em: 27 abr. 2018.

BRASIL. Ministério do Trabalho e Emprego. NR 10: Segurança em instalações e 
serviços em eletricidade. 2004. Disponível em: https://enit.trabalho.gov.br/portal/ images/Arquivos_SST/SST_NR/NR-10.pdf. Acesso em: 5 maio. 2018.

BRASIL. Ministério do Trabalho e Emprego. NR 11: Transporte, movimentação, armazenagem e manuseio de materiais. 1978a. Disponível em: http://trabalho.gov. br/images/Documentos/SST/NR/NR11.pdf. Acesso em: 5 maio. 2018.

BRASIL. Ministério do Trabalho e Emprego. NR 15: Atividades e operações insalubres. 1978b. Disponível em: http://www.guiatrabalhista.com.br/legislacao/nr/nr15. htm. Acesso em: 5 maio. 2018.

BRASIL. Ministério do Trabalho e Emprego. NR 35: Trabalho em altura. 2012. Disponível em: http://www.guiatrabalhista.com.br/legislacao/nr/nr35.htm. Acesso em: 5 maio. 2018.

BRITO, P. O. B. de. Dimensionamento de sistemas fotovoltaicos conectados à rede de distribuição: estudo de caso. 2016. 82 f. Trabalho de Conclusão de Curso (Graduação em Engenharia Elétrica) - Universidade Federal do Vale do São Francisco, Juazeiro, 2016.

CASTELLANELLI, M.; SOUZA, S. N. M.; SILVA, S. L.; KAILER, E. K. Desempenho de motor ciclo diesel em bancada dinamométrica utilizando misturas diesel/biodiesel. Engenharia Agrícola, v. 28, n. 1, p. 145-153, fev. 2008.

CENTRO DE REFERÊNCIA PARA AS ENERGIAS SOLAR E EÓLICA SÉRGIO DE S. BRITO. Tutorial da energia solar fotovoltaica. 2008. Disponível em: http://www. cresesb.cepel.br/index.php?section =com_content\&cid = tutorial_solar. Acesso em: 15 jun. 2016.

CLARO, P. B. de O.; CLARO, D. P.; AMÂNCIO, R. Entendendo o conceito de sustentabilidade nas organizações. Revista Administração, v. 43, n. 4, p. 289-300, set. 2008.

COELBA. Reajuste tarifário. 2016. Disponível em: http://www.coelba.com.br/Noticias/Pages/reajuste.aspx. Acesso em: 21 mar. 2017.

DRUMM, F. C.; GERHARDT, A. E.; FERNANDES, G. D.; CHAGAS, P.; SUCOLOTTIS, 
M. S.; KEMERICH, P. D. da C. Poluição atmosférica proveniente da queima de combustíveis derivados do petróleo em veículos automotores. Revista Eletrônica em Gestão, Educação e Tecnologia Ambiental, v. 18, n. 1, p. 66-78, abr. 2014.

FERREIRA, R. R.; SILVA FILHO, P. C. da. Energia solar FV: geração de energia limpa. 2009. Disponível em: http://connepi.ifal.edu.br/ocs/index.php/connepi/CONNEPI2010/paper/viewFile/1828/1058. Acesso em: 25 maio. 2016.

GANGA, G. M. D. Trabalho de conclusão de curso (TCC) na engenharia de produção: um guia prático de conteúdo e forma. São Paulo: Ed. Atlas, 2012.

INMETRO. Portaria $\mathbf{n}^{\mathbf{0}} \mathbf{0 0 4}$, de 04 de janeiro de 2011. Dispõe sobre requisitos de avaliação da conformidade para sistemas e equipamentos para energia fotovoltaica (módulo, controlador de carga, inversor e bateria). 2011. Disponível em: http://www.inmetro.gov.br/legislacao/rtac/pdf/RTAC001652.pdf. Acesso em: 28 jul. 2018.

LIZOTE, S. A.; ANDRADE, D. A. de; SILVA, F.; PEREIRA, R. da S.; PEREIRA, W. da S. Análise de investimentos: um estudo aplicado em uma empresa do ramo alimentício. In: SIMPÓSIO DE EXCELÊNCIA EM GESTÃO E TECNOLOGIA, 11., 2014, Rio de Janeiro. Anais [...]. Rio de Janeiro: Faculdades Dom Bosco, 2014. p. 1-14.

MOTTA, R. R.; GONÇALVES, A.; NEVES, C. das; CALÔBA, G.; NAKAGAWA, M; COSTA, R. P. da. Engenharia econômica e finanças. Rio de Janeiro: Ed. Elsevier, 2009.

NOGUEIRA, L. A. H. A crise do setor energético e a síndrome de país rico. [Entrevista cedida a] ECODEBATE. 2014. Disponível em: https://www.ecodebate.com. br/2014/06/20/a-crise-do-setor-energetico-e-a-sindrome-de-pais-rico-entrevista-com-luiz-augusto-horta-nogueira/. Acesso em: 20 fev. 2017.

SANPOWER. Proposta técnica comercial: sistema fotovoltaico on grid. [Petrolina]: [Sanpower], 2017.

SANTOS, Lucas di Paula Gama dos; SANTOS, Vivianni Marques Leite dos; DUARTE, Francisco Ricardo. Viabilidade da utilização de energia solar na Univasf - Campus Juazeiro-BA, Juazeiro: Univasf, 2017. 26 slides, color. 
UNIVERSIDADE FEDERAL DO VALE DO SÃO FRANCISCO. Relatório de gestão do exercício de 2013. Petrolina: UNIVASF, 2014. Disponível em: http://www.univasf. edu.br/acessoainformacao/arquivos/relatorio_de_gestao_UNIVASF_2013.pdf. Acesso em: 5 jun. 2016.

URTADO, Ed. S.; SANTO, V. da S.; QUINTAIROS, P. C. R.; OLIVEIRA, A. de A. Q. Aplicação do método do valor presente líquido (VPL) na análise da viabilidade econômica de projetos na indústria metal mecânica: um estudo de caso. In: ENCONTRO LATINO AMERICANO DE INICIAÇÃO CIENTÍFICA, 13., ENCONTRO LATINO AMERICANO DE PÓS-GRADUAÇÃO, 9., ENCONTRO LATINO AMERICANO DE INICIAÇÃO CIENTÍFICA JÚNIOR, 3., 2009, São José dos Campos. Anais [...]. São José dos Campos: UNIVAP, 2009. p. 1-4.

VERGARA, S. C. Projetos e relatórios de pesquisa em administração. 7. ed. São Paulo: Atlas, 2006.

Recebido em: 29/08/2017

Aceito em: 08/08/2018 